\title{
REGULAMENTAÇÃO DE BARRAGENS EM PROJETOS PARA GERAÇÃO DE ENERGIA ELÉTRICA E A GESTÃo DE RISCO
}

\author{
REGULATION OF DAMS IN PROJECTS FOR THE GENERATION OF \\ ELECTRICAL ENERGY AND RISK MANAGEMENT
}

Luciana Stephani Silva Iocca*

\begin{abstract}
Resumo: A população brasileira tem crescido a uma taxa média de $4 \%$ ao ano (IBGE, 2017) e com ela a demanda por geração de energia elétrica. No contexto brasileiro, a produção de energia de origem hidrelétrica vem sendo ampliada, diante de seu menor potencial poluidor e tendo em vista o melhor aproveitamento da capacidade hídrica do país, destacando-se o estado de Mato Grosso, reconhecido como o "estado das águas", tendo em vista que possui em seu território as nascentes de cursos d'agua que compõem importantes bacias hidrográficas. Neste contexto, o presente estudo teve por objetivo analisar como os fatores de risco, associados as barragens em projetos para geração de energia elétrica de matriz hídrica, vêm sendo avaliados no estado de Mato Grosso e qual a legislação disposta para a gestão dos riscos e segurança de barragens. A metodologia centra-se na análise da legislação nacional e estadual e no estudo de caso, essencialmente dirigida a análise do Estudo de Impacto Ambiental e do parecer técnico a respeito do Relatório de Impacto Ambiental da Usina Hidrelétrica - UHE Sinop. O estudo permite concluir que é ainda recente a regulamentação de barragens no estado de Mato Grosso, havendo insuficiência de recursos materiais e humanos para a fiscalização e monitoramento da implementação dos Planos de Barragem, impactando na efetiva gestão dos riscos provenientes destes empreendimentos.
\end{abstract}

Palavras-chave: Direito Ambiental; Estudo de Impacto Ambiental; Segurança de Barragens; Hidroelétricas; Gestão de Riscos.

\begin{abstract}
The Brazilian population has grown at an average rate of $4 \%$ per year (IBGE, 2017) and with the demand for electricity generation. In the Brazilian context, hydroelectric power generation has been expanded due to lower polluting potential and with a view to better utilization of the country's water capacity, especially the state of Mato Grosso, recognized as the "state of the water ", Considering that it has in its territory springs of water courses that compose an important hydrographic basins. In this context, the present study had as objective to analyze how the risk factors, associated to the dams in projects for generation of electric energy of hydric matrix, have been evaluated in the state of Mato Grosso and what the legislation is prepared for the management of risks and security of dams. The methodology focuses on the analysis of the national and state legislation and the case study, essentially directed to the

\footnotetext{
Doutoranda em Território, Risco e Políticas Públicas pelo Programa interuniversitário Aveiro/Coimbra/Lisboa - Portugal. Mestre em Política Social pelo Programa de Pós-Graduação em Política Social da Universidade Federal de Mato Grosso. Bacharel em Direito pela Pontifícia Universidade Católica de São Paulo. Investigadora do Centro de Estudos Sociais da Universidade de Coimbra. Contato: lucianaiocca@hotmail.com.
} 
Regulamentação de barragens em projetos para geração de energia elétrica e a gestão de risco

analysis of the Environmental Impact Study and the technical opinion regarding the Environmental Impact Report of the HPP Sinop Hydroelectric Power Plant. The study concludes that the regulation of dams in the state of Mato Grosso is still recent, with insufficient material and human resources for monitoring and monitoring the implementation of the Dam Plans, impacting on the effective management of the risks arising from these projects.

Key words: Environmental Law; Environmental Impact Study; Security of Dams; Hydroelectric; Risk management.

\section{INTRODUÇÃO}

A população brasileira tem crescido a uma taxa média de $4 \%$ ao ano (IBGE, 2017) e com ela a demanda por geração de energia elétrica. No contexto brasileiro, a produção de energia de origem hidrelétrica vem sendo ampliada, diante de seu menor potencial poluidor, frente a geração a partir de combustíveis fósseis (derivados de petróleo, carvão mineral e gás natural) e tendo em vista o melhor aproveitamento da capacidade hídrica do país. O Brasil é o terceiro país do mundo com capacidade instalada de geração de energia hidrelétrica (ANEEL, 2018) considerada uma das alternativas energética de baixo custo, com grande e rápido retorno econômico. No contexto brasileiro, o estado de Mato Grosso destaca-se como potencialidade ainda por ser explorada.

O estado de Mato Grosso, possui uma população aproximada de 2,5 milhões de habitantes, distribuídos em 145 municípios, é o terceiro estado brasileiro em dimensão territorial, com área de $901,4 \mathrm{mil} \mathrm{km}^{2}$, representa $10,55 \%$ do território nacional, com 55\% de seu território inserido na Amazônia Legal, ocupa uma posição geopolítica estratégica em relação as américas, além de ter importância por nele se encontrarem os três relevantes biomas do Brasil, nomeadamente, Amazônia, Cerrado e Pantanal e as mais importantes bacias hidrográficas do país, Paraguai, Amazonas (vários contribuintes) e a do Araguaia-Tocantins. (IBGE, 2010), evidenciando seu potencial para geração de energia elétrica de matriz hídrica.

Notadamente, a geração de energia elétrica é atividade causadora de impacto ambiental (BERMANN, 2007), possuindo diversos riscos associados, em especial os decorrentes da construção de barragens para represamento. Nesse sentido, a importância de estudos que tenham por finalidade identificar e avaliar impactos e riscos, estabelecendo medidas mitigadoras dos impactos e traçando planos estratégicos para a 
gestão dos riscos, bem como um arcabouço legislativo que exija e regulamente estes estudos, tendo em vista a aplicação dos princípios da precaução e prevenção. Diante deste quadro, o presente estudo teve por objetivo analisar como os fatores de risco, associados as barragens em projetos para geração de energia elétrica de matriz hídrica, vêm sendo avaliados no estado de Mato Grosso e qual a legislação disposta para a gestão dos riscos e segurança de barragens.

O estudo desenvolve-se a partir da análise de conteúdo dos documentos, essencialmente dirigida a legislação nacional e estadual referente as barragens, verificando as principais exigência no que tange a gestão de riscos. Posteriormente realiza-se a análise dos riscos apresentados no RIMA do projeto de criação da Usina Hidroelétrica Sinop, no Rio Teles Pires, localizado no estado de Mato Grosso, Brasil e do parecer técnico da Secretaria de Estado de Meio Ambiente - SEMA/MT para a concessão da Licença Prévia do empreendimento.

O estado de Mato Grosso fora escolhido como caso de estudo diante do seu potencial hídrico e de exploração energética, possuindo três importantes bacias, sendo de grande relevância verificar como os estudos de impacto tem considerado os riscos associados a estes empreendimentos e quais as medidas dispostas para mitigação/adaptação destes.

O trabalho encontra-se estruturado em 4 seções. Depois dessa seção introdutória, na seção 2 apresenta-se um breve estado da arte do tema, analisam-se os principais conceitos chave e como eles estão inter-relacionados. Na seção 3 apresenta-se o caso de estudo e descreve-se e discute-se os resultados da análise dos documentos legislativos, do relatório decorrente do estudo de impacto ambiental, à luz do estado de arte exposto na seção 2. Na seção 4 identificam-se as principais conclusões.

\section{A PRODUÇÃO DE ENERGIA ELÉTRICA NO BRASIL}

O Plano Nacional de Energia - PNE 2030, criado em 2005, foi o primeiro estudo de planejamento integrado dos recursos energéticos realizado no âmbito do Governo brasileiro. O estudo foi conduzidos pela Empresa de Pesquisa Energética EPE, cujas atribuições, definidas pela Lei nº10.847/2004, incluem a promoção dos estudos de potencial energético, “[...] visando fornecer subsídios para a formulação de uma estratégia de expansão da oferta de energia econômica e sustentável com vistas ao atendimento da evolução da demanda, segundo uma perspectiva de longo prazo"(EPE, 2007). 
Regulamentação de barragens em projetos para geração de energia elétrica e a gestão de risco

Dentre as fontes energéticas contempladas no PNE, estão as de origem hídrica, compreendidas as Usinas Hidrelétricas - UHE e as Pequenas Usinas Hidrelétricas - PCHs, que se constitui numa alternativa de obtenção de energia elétrica a partir do aproveitamento do potencial hidráulico de um determinado trecho de um rio, normalmente assegurado pela construção de uma barragem e pela consequente formação de um reservatório (BERMANN, 2007).

Os estudos desenvolvidos pela EPE, quando da criação do PNE 2030, concluíram que as regiões norte e centro-oeste do país figuravam como as regiões com maior potencial hidrelétrico, ainda não aproveitados (Figura 1), direcionando investimentos para a realização de Avaliação de Impacto Ambiental nessas bacias.

Figura 1 - Distribuição geográfica do Potencial Hidrelétrico a aproveitar no Brasil

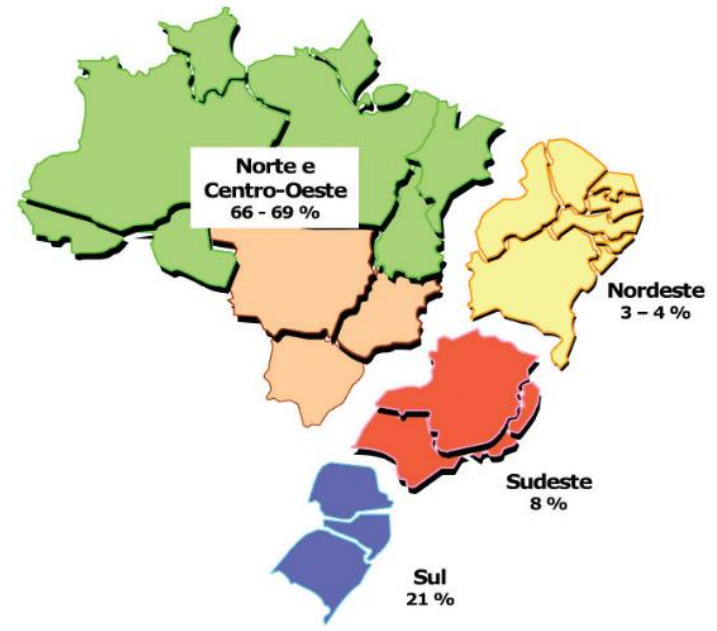

Fonte: Plano Nacional Energético 2030 (EPE, 2005)

No que tange a capacidade de geração de energia do Brasil, o país possui no total 4.899 empreendimentos em operação, totalizando 157.061.203 KW de potência instalada, estando prevista para os próximos anos uma adição de 19.100.181 KW na capacidade de geração do país, proveniente de 212 empreendimentos em construção e 413 previstos. No atual contexto do país, a hidreletricidade é responsável por cerca de 60,68\% da capacidade instalada de geração de energia (ANEEL, 2018).

O EPE (2018) divulgou a existência de 29 estudos em andamento e previsão de serem iniciados outros 14 , referentes ao planejamento da expansão da transmissão. 
Contudo, o desenvolvimento do setor energético, focado nos recursos hídricos, deve considerar os impactos socioambientais destes empreendimentos, bem como os riscos a eles associados. Nesse sentido, a importância da legislação ambiental e dos instrumentos por ela criados, dentre eles a exigência do Estudos de Impacto Ambiental, indispensável para a criação de plano estratégico para a gestão dos riscos.

\subsection{POLÍTICAS DO SETOR ENERGÉTICO}

A preocupação com o ambiente, vislumbrando-o como direito fundamental, ganhou força no contexto internacional a partir da Conferência das Nações Unidas sobre Meio Ambiente em 1972, também conhecida como Conferência de Estocolmo, conferindo enfoque preventivo aos problemas ambientais, os reconhecendo como problema global, crescente e, frequentemente, irreversíveis. O princípio da prevenção, dessa forma, consagra a obrigatoriedade de tomar medidas para controlar os riscos comprovados.

Essa nova perspectiva influenciou a criação de legislações nacionais voltadas a concretização desses princípios, dentre elas a Política Nacional de Meio Ambiente (PNMA), instituída pela Lei $\mathrm{n}^{\circ}$ 6.938/81, regulamentada pelo Decreto $\mathrm{n}^{\mathrm{o}}$ $88.351 / 83$, o qual passou a exigir a licença ambiental para toda e qualquer atividade com potencial para causar impacto ambiental significativo (art. 18, Decreto $\mathrm{n}^{\circ}$ 88.351/83). A concessão de licença ambiental, por sua vez, está condicionada a apresentação do Estudo de Impacto Ambiental (EIA).

O EIA visa avaliar a viabilidade ambiental do projeto e tem suas diretrizes gerais de elaboração estabelecidas pela Resolução 001/86 do Conselho Nacional do Meio Ambiente (CONAMA), órgão Superior do Sistema Nacional do Meio Ambiente (SISNAMA), responsável pela regulamentação e implementação da PNMA.

Posteriormente, um novo paradigma para gestão dos riscos é proposto a partir do princípio da precaução, o qual começou a ganhar reconhecimento doutrinal na década de 90, passando a ser incorporado ao Direito Internacional com maior frequência, surgindo nas Convenções criadas no contexto da Conferência das Nações Unidas sobre Ambiente e Desenvolvimento. O princípio da precaução estabelece a obrigatoriedade de tomar medidas eficazes para mitigar ameaças de riscos ambientais irreversíveis, mesmo diante da ausência de certeza científica a respeito deles (ARAGÃO, 2008). Ambos os princípios impõem a adoção tempestiva de medidas antecipatória, capazes de evitar os efeitos ambientais indesejáveis, contudo, enquanto o R. Fac. Dir. UFG, v. 42, n. 3, p.202-224, set./dez. 2018 
Regulamentação de barragens em projetos para geração de energia elétrica e a gestão de risco

princípio da prevenção visa o controle de riscos comprovados, o princípio da precaução centra-se nos riscos hipotéticos ou potenciais (ARAGÃO, 2008; 2012).

No contexto dos empreendimentos destinados a geração de energia de matriz hidrelétricas, observados os dispositivos da PNMA, a regulamentação se dá com fulcro na Lei n. ${ }^{\circ}$ 9.433/1997, que define a Política Nacional de Recursos Hídricos e a Lei $n^{\circ}$ 12.334/2010, que estabelece a Política Nacional de Segurança de Barragens PNSB. O princípio da precaução encontra-se consagrado na PNSB, a qual utiliza-se do termo "risco e dano potencial associado", deixando claro que os riscos hipotéticos também devem ser considerados para efeito de adoção de medidas mitigadoras no contexto da gestão de riscos.

$\mathrm{Na}$ implementação dos empreendimentos hidrelétricos, dois órgãos concorrem para sua regulação, a Agência Nacional de Energia Elétrica (ANEEL), criada pela Lei no 9.427 no ano de 1996, e a Agência Nacional das Águas (ANA), criada pela Lei $n^{\circ} 9.984$ no ano de 2000. Cabendo aos órgãos ambientais (federal e estadual) a fiscalização quanto a aplicabilidade da legislação vigente, em especial a que se refere ao atendimento dos requisitos para implementação do empreendimento e seu funcionamento. Dentre os requisitos a serem atendidos, encontra-se o Estudo de Impacto Ambiental - EIA e seu respectivo Relatório - RIMA, imprescindíveis para a obtenção da Licença Prévia, concedida na fase preliminar do planejamento da atividade.

O EIA e seu respectivo relatório (RIMA) é um dos instrumentos da Política Nacional do Meio Ambiente - PNMA (Lei $n^{\circ}$ 6.938/81), competindo ao CONAMA, com fulcro no art. $8^{\circ}$, II, determinar, quando necessário, a realização de estudos das alternativas e das possíveis consequências ambientais de projetos públicos ou privados, requisitando aos órgãos públicos e entidades privadas, as informações indispensáveis para apreciação dos estudos de impacto ambiental, e respectivos relatórios, no caso de obras ou atividades de significativa degradação ambiental.

O estudo deve atender critérios básicos, segundo Decreto ${ }^{\circ} 88.351 / 83$, que regulamenta a PNMA, quais sejam: diagnóstico ambiental da área; descrição da ação proposta e suas alternativas; a identificação, análise e previsão dos impactos significativos, positivos e negativos; sendo sua elaboração realizada por técnicos habilitados e seu custeio de responsabilidade do empreendedor. A Resolução 237/97 do CONAMA, por sua vez, exige que o EIA/RIMA apresente análise preliminar de risco, 
mas é omissa em relação aos elementos integrantes desta análise, o que pode contribuir com estudos superficiais no que tange a identificação e avaliação dos riscos e consequentes medidas mitigadoras.

Em que pese a obrigatoriedade na apresentação do EIA/RIMA, pesquisas têm apontado a baixa qualidade desses estudos no Brasil e em outros países (ALMEIDA; et. al, 2015; MONTAÑOS; et. al, 2014). Dentre as principais fatores que contribuem para esta baixa qualidade, aponta-se: a falta de competência na coordenação dos estudos; a baixa qualidade das análises técnicas, com a utilização de termos genéricos ou insuficientes; ausência de independência da equipe que elabora o EIA, a ausência ou baixo número de alternativas, a prevalência dos aspectos econômicos sobre os ambientais na escolha de alternativas e a falta ou restrita participação da comunidade na elaboração dos EIA, bem como a ausência de linguagem acessível, o que compromete diretamente a oportunidade de envolvimento da sociedade (PINHO; et al, 2007).

Não obstante a necessidade de apresentação do EIA/RIMA, com a publicação da Lei ${ }^{\circ}$ 12.334, passou a ser exigido dos empreendimentos o Plano de Segurança de Barragem, um dos instrumentos da Política Nacional de Segurança de Barragens, visando a gestão dos riscos associados.

\subsection{BARRAGENS E RISCOS ASSOCIADOS}

A Estratégia Internacional para Redução de Desastres da Organização das Nações Unidas (EIRD/ONU, 2007), define o risco como a probabilidade de que ocorram consequências prejudiciais e/ou danos, resultantes da interação entre as ameaças e a vulnerabilidade. Podendo ser expresso pela equação: RISCO = Probabilidade X Consequência (COROMINAS; et.al, 2015). A gestão do risco, nesse sentido, visa evitar os danos decorrentes dos riscos identificados e, ou, mitigar os seus impactos (compreendidos como perdas de vida, danos tangíveis e intangíveis). A gestão do risco, por sua vez, pode ser compreendida como "[...] uma abordagem sistemática voltada para o estabelecimento do melhor curso de ação possível em ambiente marcado por incertezas por meio da identificação, compreensão, atuação objetiva e comunicação de questões que envolvam riscos" (TBS, 2001). A gestão tem a finalidade de controlar os riscos por meio de um conjunto de atividades integradas que compreendem decisão, mitigação, prevenção, identificação, planeamento de emergência, monitoramento e a comunicação dos riscos (ENAP, 2003). Neste sentido, a gestão do risco deve ocorrer R. Fac. Dir. UFG, v. 42, n. 3, p.202-224, set./dez. 2018 
Regulamentação de barragens em projetos para geração de energia elétrica e a gestão de risco

tendo em vista estabelecer políticas e estratégias a fim de reduzir os impactos de ameaças e, consequentemente, a ocorrência de possíveis desastres. A gestão do risco, compreende, assim, ações de prevenção, mitigação e preparação, com uma participação ativa e articulada da sociedade (EIRD/ONU, 2007).

Em que pese os empreendimentos hidrelétricos serem vislumbrados como de menor impacto ambiental, se comparado à outras fontes de produção de energias, como as provenientes de combustíveis fósseis, esses não se revelam sustentáveis, gerando uma série de impactos decorrentes de sua implantação e funcionamento, bem como riscos associados à essas atividades. Dentre os principais impactos, destacam-se a alteração no regime hidrológico, assoreamento do reservatório, alteração no ecossistema, emissão de gases do efeito estufa e deslocamento da população (ALMEIDA; et.al, 2015; MONTAÑO; et.al, 2014; BERMANN, 2007).

No que tange aos riscos associados, destacam-se os decorrentes do rompimento, vazamento ou mau funcionamento das barragens. A ruptura de uma barragem é um risco tecnológico, resultante de acidentes que decorrem da atividade humana (BECK, 2004), com consequências, por vezes, imprevisíveis. Neste sentido, a importância do Plano de Segurança de Barragem como instrumento de controle do comportamento das barragens relativos aos aspectos estruturais, hidráulico-operacionais e ambientais, evitando acidentes, ou minorando as suas consequências. Dentre os mecanismos dispostos para o monitoramento de barragens, segundo a legislação vigente, se dá por meio da sua classificação, visando definir o grau de risco associado. As barragens, assim, são estruturas que devem ser classificadas pelos agentes fiscalizadores por categoria de risco, por dano potencial associado e pelo seu volume, com fulcro no art. $7^{\circ}$, da Lei $n^{\circ} 12.334 / 2010$, que estabelece a Política Nacional de Segurança de Barragens.

A classificação por categoria de risco é feita em alto, médio ou baixo, leva em conta aspectos estruturais e funcionais da barragem, bem como suas características técnicas, estado de conservação e o atendimento ao Plano de Segurança da Barragem. A classificação por categoria de dano potencial associado, também se dá em alto, médio ou baixo, considerando o potencial de perdas de vidas humanas, dos impactos econômicos e socioambientais decorrentes da ruptura da barragem. Há, ainda, a classificação quanto ao volume das barragens (SAMPAIO, 2016). A classificação se dá 
com base nas informações prestadas pelo empreendedor. Neste ponto, a autodeclaração do empreendedor apresenta-se como ponto falho na norma, tendo em vista que se pressupõe a ausência de imparcialidade diante dos evidentes interesses envolvidos e, por outro lado, os órgãos físcalizadores não contam com recursos humanos e materiais suficientes para realizar a verificação da veracidade técnica das informações prestadas (SAMPAIO, 2016), o que contribui diretamente para que o sistema de classificação não seja um instrumento efetivo da Política de Segurança de Barragem, não atingindo sua finalidade na gestão de riscos.

Ainda, conforme Resolução 143/2012 do Conselho Nacional de Recursos Hídricos - CNRH, as barragens devem ser classificadas a cada cinco anos pelos órgãos fiscalizadores, a partir das informações prestadas pelo próprio empreendedor e, caso não as apresente, o órgão fiscalizador deve aplicar a pontuação máxima para todos os critérios ou para os faltantes. Contudo, segundo dados do Relatório de Segurança de Barragens, da Agência Nacional das Águas (ANA, 2016, p. 36), em 2015, somente 13\% do total das barragens cadastradas no país possuíam classificação quanto ao risco e ao dano potencial associado, em 2016, esse número era de 16\%, (ANA: 2017; p. 21), no que tange especificamente as barragens destinadas a produção de energia hidrelétrica, não há dados atualizados fornecidos pela ANEEL, sendo a última divulgação referente à 2013, evidenciando não só o descumprimento da legislação, mas a ausência de fiscalização dos órgãos responsáveis.

O desastres ligados ao rompimento de barragens possuem recorrência mundial e, na história recente do Brasil ${ }^{1}$, configura-se como o maior desastre ambiental do país, com impactos sem precedentes, impossíveis de serem quantificados em sua totalidade. No contexto brasileiro, só em 2004, foram registradas a ruptura de mais de 200 barragens de diversos tamanhos e tipos, como resultado da combinação de eventos meteorológicos adversos somados a falta de manutenção de infraestrutura hídrica (BRASIL, 2005). Evidenciando, a importância de um plano de gestão de riscos e plano de emergência, pautados em efetivo estudo sobre os riscos e danos associados.

No caso de Mato Grosso, o estado não contava com uma legislação específica sobre barragens, sendo recente a aprovação, em 2017, da Resolução SEMA $\mathrm{n}^{\circ}$ 99, não havendo previsão para o início da fiscalização e classificação das barragens, segundo critérios da Política Nacional de Segurança de Barragem.

Com base nos Relatórios de Segurança de Barragens - RSB (ANA: 2016 e 2017), verifica-se que em 2015 existia no âmbito da SEMA uma equipe trabalhando R. Fac. Dir. UFG, v. 42, n. 3, p.202-224, set./dez. 2018 
Regulamentação de barragens em projetos para geração de energia elétrica e a gestão de risco

com o tema "Segurança de Barragem", mas referida equipe era composta de 2 pessoas. Em 2016, a equipe passou a ser composta por 4 pessoas, mas em setor que não possui atribuição de segurança de barragem. Entretanto, o número de barragens cadastradas em Mato Grosso que era de 140 em 2015, passou para 167 em 2016, evidenciando a incapacidade técnica do órgão para realizar as fiscalizações no estado.

Os Relatórios (ANA: 2016 e 2017), identificaram, ainda, que no estado de Mato Grosso, das 140 barragens classificadas em 2015, 138 possuíam classificação apenas quanto aos Danos Potenciais Associados - DPA, não sendo classificadas quanto a categoria Risco - CRI, havendo 2 barragens sem informações a respeito de classificação, não sendo realizada nenhuma fiscalização no período de 2015 (Figura 2). No ano de 2016, com 167 barragens cadastradas, o número de barragens classificadas quanto aos Danos Potenciais Associados - DPA e quanto a categoria Risco - CRI foi ampliando significativamente. Contudo, apenas uma vistoria foi realizada, retornando um plano de segurança de barragem no período (Figura 2).

Figura 2 - Fiscalização de barragens de usos múltiplos e de resíduos 


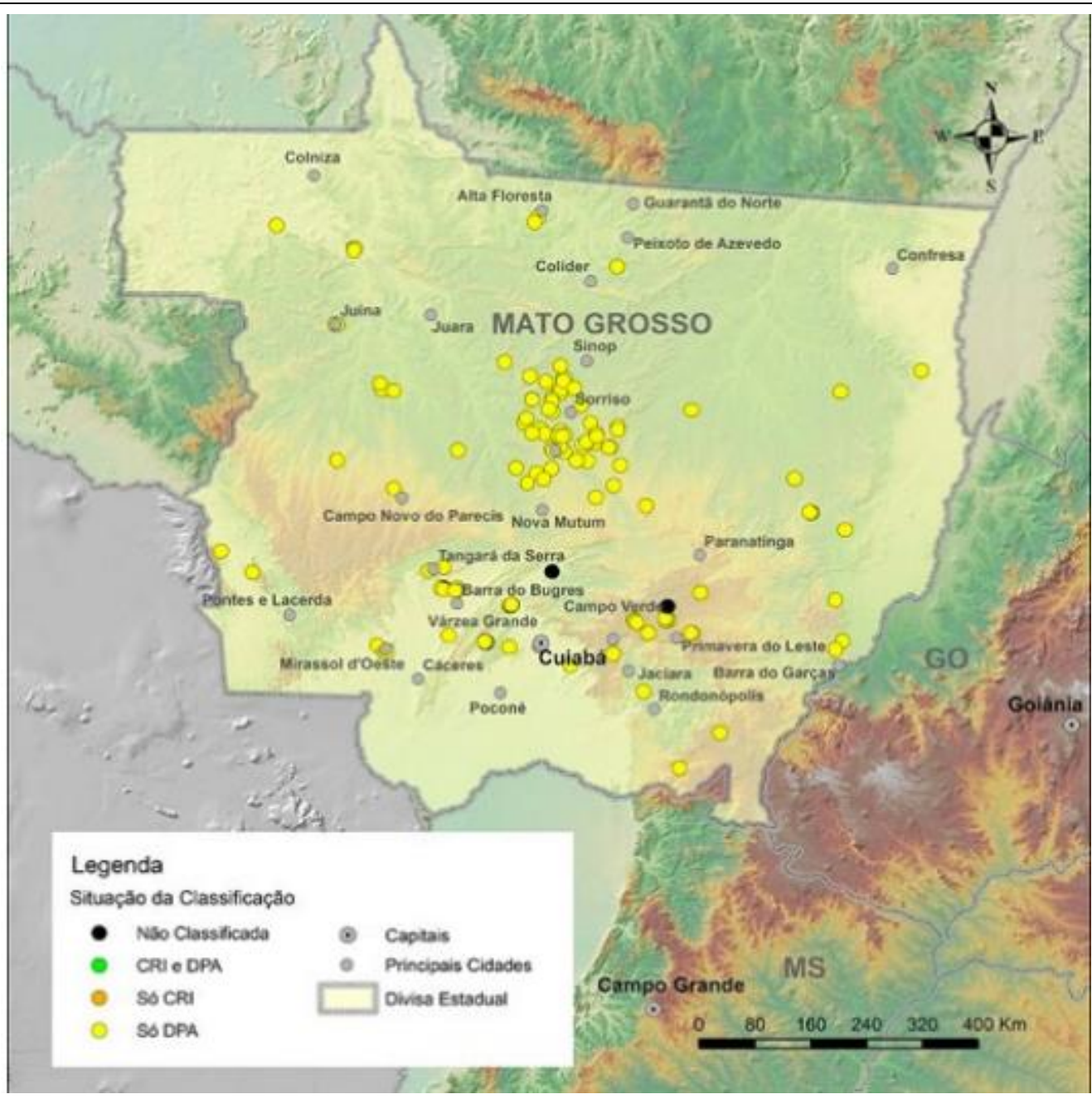

Fonte: (ANA, 2016, p. 138)

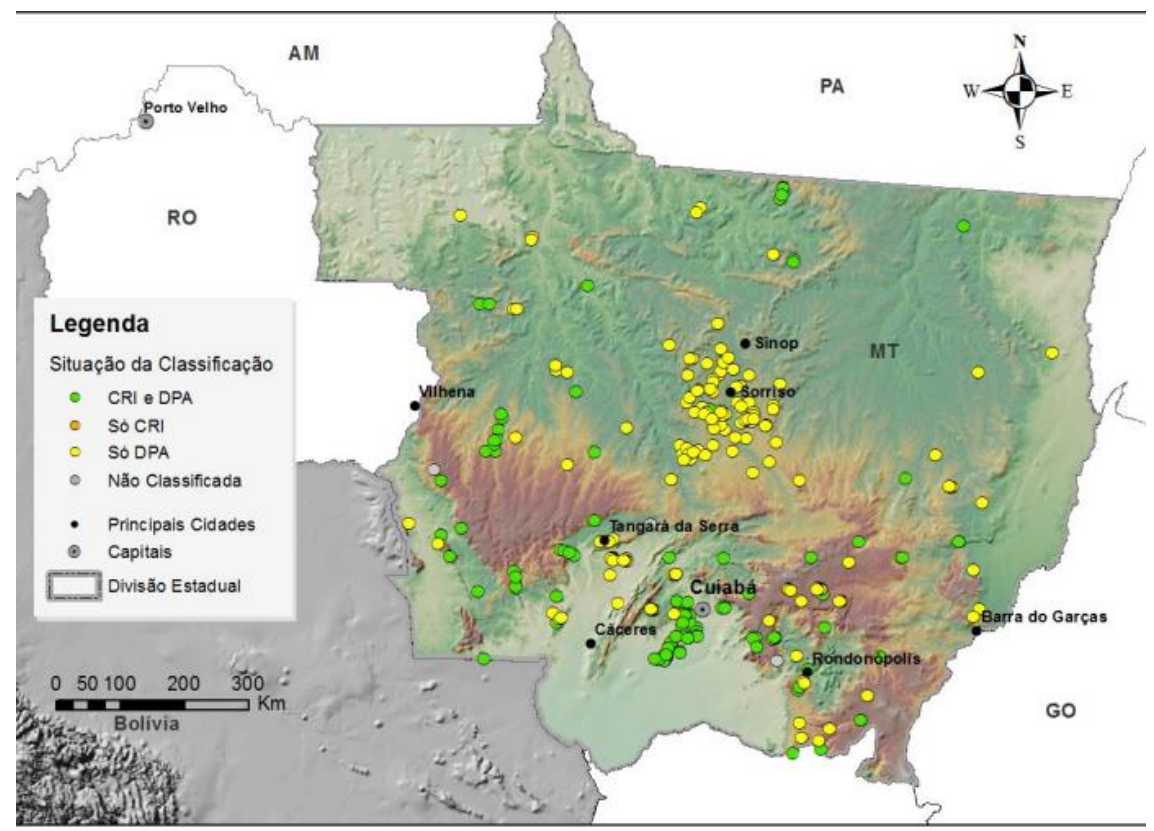

Fonte: (ANA, 2017, p. 138) 
Regulamentação de barragens em projetos para geração de energia elétrica e a gestão de risco

O reduzido número de componentes da equipe técnica responsável pela fiscalização, aliada à ausência de setor com atribuição específica certamente contribui com o quadro apresentado. Entretanto, salienta-se que os dados apresentados nos RSB são restritos as barragens destinadas a usos múltiplos e de resíduos industriais, uma vez que os dados específicos sobre barragens destinadas a geração de energia hidrelétrica não possuem base de dados atualizada pela ANEEL desde 2013. Segundo informações prestadas pela ANEEL, referida base de dados destina-se especificamente a fiscalização da geração de energia elétrica e que "[...] o cadastro com a finalidade de fiscalização da segurança de barragem se encontra em elaboração" (ANA, 2017, p. 33).

O baixo índice de classificação de barragens de, o baixo número de planos de segurança e dos respectivos planos de emergência, resultantes de uma deficiente atuação dos órgãos fiscalizadores, ampliam a importância dos Estudos de Impacto Ambiental, uma vez que estes passam a ser o único instrumento para identificar os impactos ambientais, riscos e danos associados aos empreendimentos.

\section{O CASO DA USINA HIDRELÉTRICA DE SINOP NO RIO TELES PIRES}

O projeto da Usina Hidrelétrica de Energia de Sinop foi proposto para o trecho estadual do Rio Teles Pires. As obras estão localizadas na margem direita no município de Claudia e na margem esquerda no município de Itaúba. O reservatório da UHE-Sinop atingirá os municípios de Sinop, Claudia, Sorriso, Itaúba e Ipiranga do Norte, todos no Estado do Mato Grosso, com potência instalada de 400 MW, um reservatório de $383,4 \mathrm{~km}^{2}$ e uma barragem com 53 metros de altura que tem como empresa consultora e projetista Themag Engenharia e Gerenciamento.

Em 31 de março de 2010 foi protocolado o requerimento de Licença Prévia - LP. Em 06 de abril de 2010 foi protocolado ofício da EPE encaminhando para a Secretaria Estadual de Meio Ambiente - Sema cópia de ofício do Ibama estabelecendo competência para o licenciamento ambiental da UHE-Sinop. Em 31 de março de 2010 foi protocolado o EIA e o RIMA do empreendimento. Em 19 de abril de 2010 ocorreu uma reunião da equipe técnica da Sema e a equipe técnica que elaborou o Estudo de Impacto Ambiental da UHE Sinop. Em 28 de abril de 2010 foi publicado em Diário 
Oficial a Portaria $n^{\circ} 050$ que designa a equipe técnica da Sema para análise do Eia/Rima da UHE-Sinop.

As participações públicas se restringiram às Audiências Públicas, direcionadas para a apresentação à sociedade civil do EIA/RIMA da UHE-Sinop, ocorreram em 16 de novembro de 2010 na Cidade de Ipiranga do Norte. Em 17 de novembro de 2010, na Cidade de Sorriso. Em 17 de novembro foi suspensa a Audiência Pública na cidade de Sinop em função de decisão judicial, por dúvidas no EIA e reivindicação de Movimentos Sociais (Atingidos por Barragem, Assentamento Panorama, Assentamento Gleba Celeste, Associação dos pescadores e Ribeirinhos). Em 19 de novembro de 2010, na Cidade de Cláudia. Em 20 de novembro de 2010, na Cidade de Itaúba. Em 25 de novembro de 2010, na Cidade de Sinop.

\subsection{A BACIA HIDROGRÁFICA DO RIO TELES PIRES}

O Rio Teles Pires (Figura 3) é um dos principais afluentes da bacia hidrográfica amazônica, abrangendo parte dos estados de Mato Grosso e Pará, possuindo, aproximadamente, $141.483 \mathrm{~km}^{2}$ de área de drenagem e $3.463 \mathrm{~km}$ de perímetro (VEIGA; et. al, 2013).

Figura 3 - Bacia Hidrográfica do Rio Teles Pires

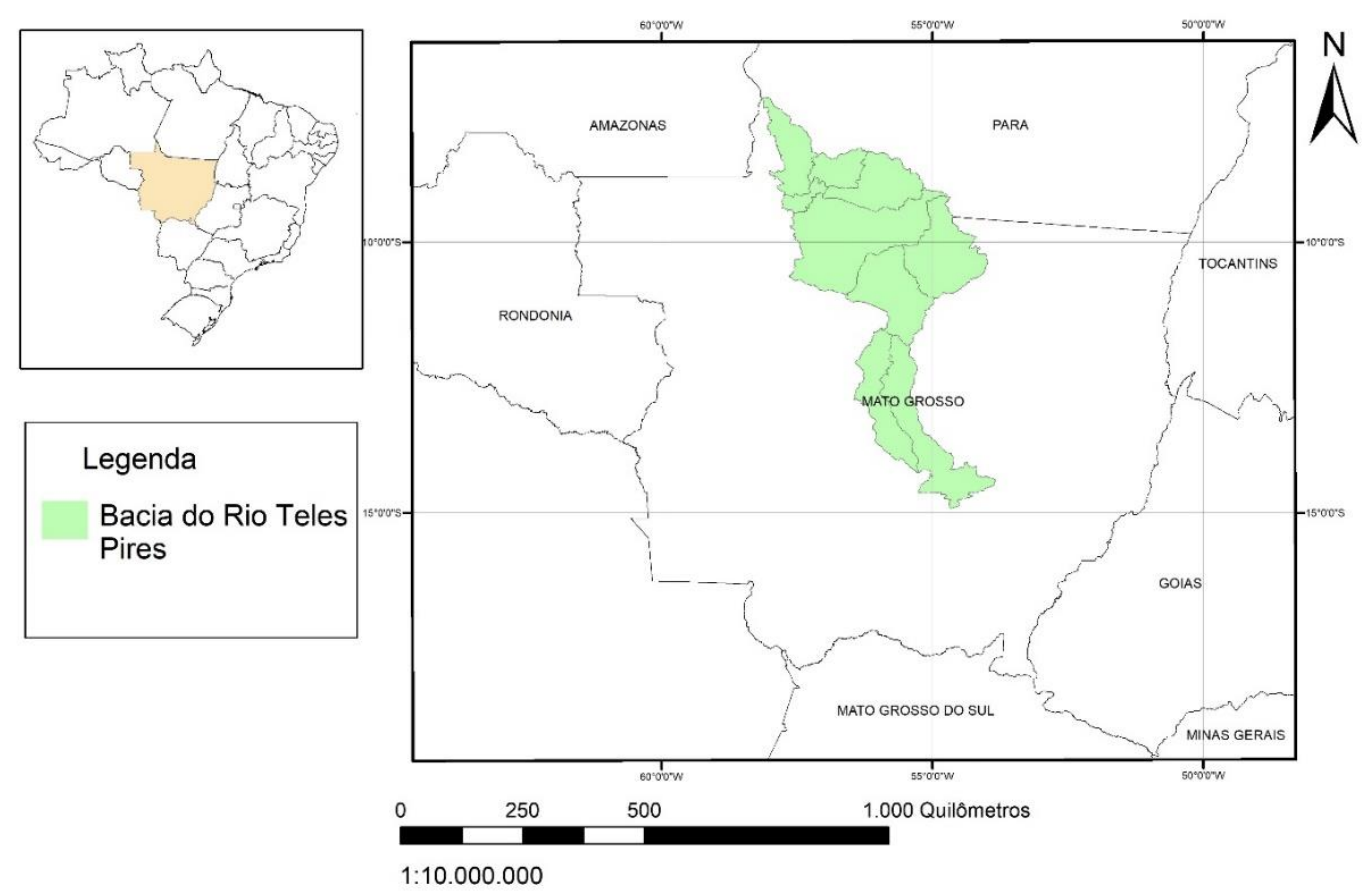

Fonte: Base Cartográfica Ministério do Meio Ambiente e Serviço Geológico do Brasil, 2018. 
Regulamentação de barragens em projetos para geração de energia elétrica e a gestão de risco

Em 2005, um consórcio, formado pelas estatais Eletrobrás, Furnas e Eletronorte resolveram aproveitar este potencial hidrelétrico, com o projeto de implantação de 6 UHEs (Figura 4), das quais cinco no Rio Teles Pires e uma na foz do Rio Apiacás, um dos afluentes do Rio Teles Pires, com capacidade de geração de 3.600 MW.

Figura 4 - UHEs na Bacia Hidrográfica do Rio Teles Pires

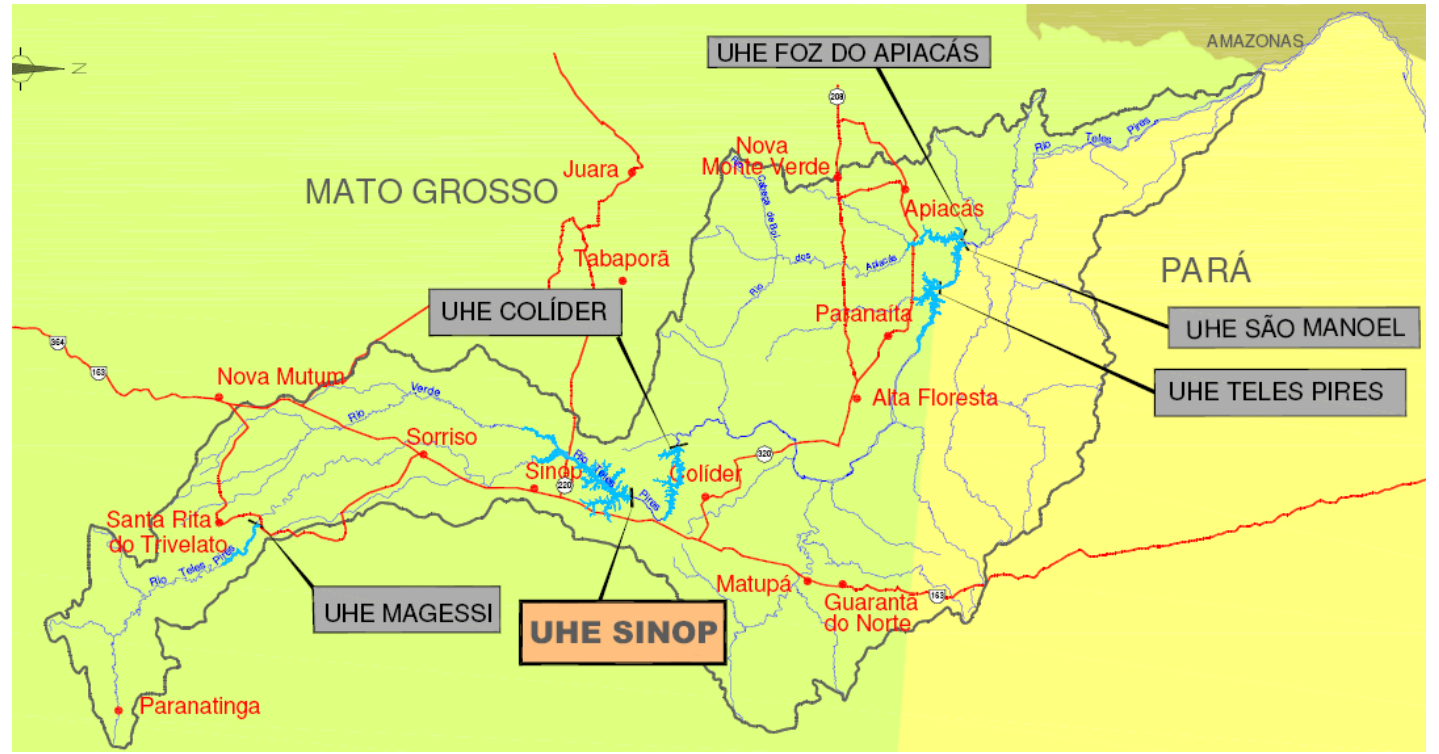

Fonte: (Sema, 2010)

As UHEs encontram-se em fase de construção, todas com os licenciamentos aprovados pelo órgão estadual. Contudo, no que tange ao Plano de Segurança de Barragens, nenhuma delas possui o plano, sendo recente a criação da Resolução Estadual no 99/2017, que estabelece a periodicidade de execução ou atualização, a qualificação dos responsáveis técnicos, o conteúdo mínimo e o nível de detalhamento do Plano de Segurança da Barragem, das Inspeções de Segurança Regular e Especial, da Revisão Periódica de Segurança de Barragem e do Plano de Ação de Emergência, das barragens fiscalizadas pela SEMA, conforme a Política Nacional de Segurança de Barragens. 


\subsection{EIA/RIMA DA UHE-SINOP}

A qualidade do EIA/RIMA está diretamente ligado ao rigor metodológico na coleta e análise dos dados, demandando conhecimento técnico e equipe multidisciplinar, contudo o EIA /RIMA da UHE - Sinop não apresenta a metodologia de forma clara, com ausência dos critérios utilizados para identificação e avaliação dos impactos. A metodologia está descrita em termos vagos, sendo apresentada no RIMA em 7 linhas que nada dizem.

O Relatório dispõe sobre possíveis impactos de forma genérica, enquanto os riscos associados e as medidas mitigadoras estão divididos em Riscos na Fase de Implantação do Empreendimento e Riscos na Fase de Operação e Manutenção do Empreendimento. Estão compreendidos nos riscos na fase de implantação do empreendimento:

\footnotetext{
- Ruptura de ensecadeiras - estruturas provisórias de terra e rocha que têm a finalidade de permitir a implantação das obras definitivas a seco, protegendo as áreas de trabalho contra a invasão das águas do rio.

- Ruptura de taludes de escavação - Para implantação das estruturas barragens de terra, casa de força, vertedouro, barragens de concreto e outras há necessidade de escavações em solo e rocha em que os taludes chegam a ultrapassar $50 \mathrm{~m}$ de altura.

- Outros tipos de acidentes - Diversos outros tipos de acidentes estão relacionados à fase de implantação do empreendimento com eventuais consequências, tais como:

- Acidentes com veículos e equipamentos provocando incêndio, derramamento de combustível, derramamento de materiais diversos que possam ser carreados ao rio, etc.;

- Acidentes em depósitos de líquidos inflamáveis ou com veículos de transporte desses materiais, provocando derramamento de materiais, incêndio, explosão, etc.;

- Atos de sabotagem (RIMA UHE Sinop, 2010, p. 120-122).
}

Os Riscos na Fase de Operação e Manutenção do Empreendimento compreendem:

\footnotetext{
- Ruptura de barragem de terra por galgamento - Galgamento é definido como "fenômeno que ocorre quando o nível d'água do reservatório se eleva muito, decorrendo no escoamento por sobre a crista da barragem (não vertedouro de soleira livre), de modo contínuo ou intermitente."

- Ruptura de estruturas por problemas geotécnicos e geológicos - É também um dos tipos mais frequentes de acidentes, notadamente com barragens de terra, relacionando-se a problemas de piping, aparecimento de fissuras no maciço de terra, instabilidade de taludes, infiltração de água pelo contato com ombreira ou fundação, erosões progressivas, etc.

- Outros tipos de acidentes - Diversos fatores podem contribuir para a ocorrência de um acidente, como as reações químicas no concreto, sendo as mais comuns as reações álcali-agregados e ataque de sulfatos, aumento de subpressão na fundação das estruturas, atos de terrorismo ou de sabotagem, dentre outros (RIMA UHE Sinop, 2010, p. 123).
} 
Regulamentação de barragens em projetos para geração de energia elétrica e a gestão de risco

A partir dos impactos e dos riscos identificados, o RIMA apresenta uma tabela onde prevê as medidas mitigadoras, compensatórias e os programas de controle e monitoramento. Entretanto referidas medidas se limitam a medidas não estruturais, voltadas aos impactos econômicos, sociais e ambientais, não fazendo nenhuma referência aos riscos associados à ruptura de barragem.

Em novembro de 2010, o Ministério Público Federal - MPF ingressou com Ação Civil Pública, pleiteando a nulidade do EIA/RIMA da UHE em todo Rio Teles Pires, identificando uma série de violações legais, em especial as dispostas na Resolução CONAMA n. ${ }^{\circ}$ 01/1986, constatando a existência de 10 vícios, a saber: a) O EIA não contempla alternativas tecnológicas do projeto (Art. $5^{\circ}$, I); b) O EIA não apresenta o confronto com a hipótese de não execução do projeto (Art. $5^{\circ}$, I); c) O EIA não apresenta a análise dos impactos das alternativas do projeto (Art. $6^{\circ}$, II da Resolução CONAMA n. ${ }^{\circ}$ 01/1986); d) O RIMA não apresenta informações sobre os objetivos e as justificativas do empreendimento de forma clara, tampouco há a discussão da relação e da compatibilidade do UHE com as políticas setoriais, planos e programas governamentais (Art. $9^{\circ}$, I); e) O RIMA não apresenta a descrição das alternativas tecnológicas do projeto, bem como não especificou, nas fases de construção e operação, a área de influência, as matérias primas, as fontes de energia, os processo e técnicas operacionais, os prováveis efluentes, emissões, resíduos e perdas de energia e os empregos diretos e indiretos a serem gerados (Art. $9^{\circ}$, II); f) O RIMA não apresenta a descrição dos prováveis impactos ambientais da implantação e da operação da atividade em relação às alternativas do projeto, com a indicação dos horizontes de tempo de incidência dos impactos e indicando os métodos, técnicas e critérios adotados para sua identificação, quantificação e interpretação (Art. 9º, IV); g) O RIMA não apresenta a caracterização da qualidade ambiental futura da área de influência em relação às possíveis alternativas tecnológicas e locacionais, nem com a hipótese de não realização do empreendimento (Art. 9, V); h) O RIMA não apresenta a descrição do efeito esperado das medidas mitigadoras previstas em relação aos impactos negativos, mencionando aqueles que não puderem ser evitados, e o grau de alteração esperado, limitando-se a listar as medidas mitigadoras e compensatórias associadas aos diversos impactos ambientais (Art. 9, VI); i) O RIMA não apresenta recomendação quanto à 
alternativa mais favorável, nem são apresentadas informações que permitam comparar diferentes possibilidades e alternativas, do modo a facilitar a formação de juízo de valor sobre a conveniência ou não de instalação do empreendimento (Art. 9', VIII); j) O RIMA não foi apresentado de forma objetiva e adequada a sua compreensão, com informações traduzidas em linguagem acessível, ilustradas por mapas, cartas, quadros, gráficos e demais técnicas de comunicação visual, de modo que se possa entender as vantagens e as desvantagens do projeto, bem como todas as consequências ambientais de sua implementação. Isto porque a linguagem empregada frequentemente utiliza termos técnicos, de difícil entendimento pelo público leigo. Há longos trechos apenas com texto, sem o recurso de gráficos e quadros sintéticos que ajudem a explicar e contextualizar os dados apresentados. Não foram apresentadas informações suficientes para permitir a compreensão dos impactos do empreendimento comparativamente com possíveis alternativas (Art. $9^{\circ}$, parágrafo único).

O pedido de liminar do MPF foi deferido, entretanto, em sede de recurso, a liminar foi suspensa sob o fundamento de que, "se ainda não existe ato concreto a causar danos [...] revela-se precipitada a restrição judicial em relação a eles, posto que impossível verificar a sua (i)legalidade." Salientando, ainda, que a liminar se apresentava como medida extremamente prejudicial à ordem e à econômica pública. (TRF1 - Suspensão de Liminar/ACP nº 0078534-70.2012.4.01.0000/MT. Des. Mário César Ribeiro. DJ 14/12/2010).

Atualmente a ACP encontra-se em tramitação perante a $2^{\mathrm{a}}$ Vara Federal de Sinop, estando os autos em posse da Procuradoria Federal para manifestação em nome da ANEEL. Contudo, a instalação da UHE-Sinop, sob concessão, por 35 anos, da Companhia Energética de Sinop (CES), encontra-se na fase de "montagem dos itens principais da fundação metálica geral da primeira turbina", 2 com previsão de início do enchimento do reservatório para setembro de 2018 e início da geração de energia para dezembro de 2018.

\subsection{A GESTÃO DO RISCO NA UHE - SINOP}

Ao analisar o caso da UHE-Sinop, verifica-se que não houve efetiva participação social, sendo restrita à apresentação do EIA/RIMA, em direta violação ao princípio de gestão democrática de bacias, previsto na Política Nacional de Gestão dos Recursos Hídricos. Ademais, a gestão de riscos relacionados a ruptura de barragem é inviabilizada diante da ausência do Plano de Segurança de Barragens, não havendo a R. Fac. Dir. UFG, v. 42, n. 3, p.202-224, set./dez. 2018 
Regulamentação de barragens em projetos para geração de energia elétrica e a gestão de risco

previsão de medidas mitigadoras, dentre elas a de monitorização e sistema de alerta, considerando a existência de comunidades próximas as barragens, tampouco, um Plano de Ação Emergencial, no caso de ruptura.

Outro ponto relevante é que os estudos de impacto cumulativo ou sinérgicos, que tem por finalidade demonstrar os impactos de uma barragem sobre a outra (quando há várias em um mesmo curso de rio), não levam em conta os impactos que um desastre em uma das barragens tem sobre as demais, constituindo também uma grande falha, a qual agrava os riscos associados as UHEs do Rio Teles Pires, tendo em vista que não é possível precisar os riscos advindos do impacto cumulativo (SANCHEZ, 2006).

O RIMA traz itens que influenciam na vazão de modo subjetivo, sem especificar os reais impactos e consequente gravidade de riscos associados. A exemplo disso, o uso do termo genérico "mais significativo", sem especificar a vazão, baseada numa série histórica dos períodos de cheias, por exemplo. "Já os trechos médio e inferior, apresentam índices pluviométricos maiores aliados ao formato mais retangular e largo, permitindo assim a formação de maiores deflúvios e a possibilidade de picos de cheias mais significativos" (RIMA UHE Sinop, 2010, p. 12).

Outro ponto que merece atenção é o fato de o próprio RIMA reconhecer a necessidade de mais estudos, como os relacionados aos transportes de sedimentos. "Em que pese o fato dos poucos dados disponíveis, mostram que o transporte de sedimentos na bacia a montante da UHE SINOP ainda é muito baixo, não sendo um fator de preocupação para o futuro do empreendimento" (RIMA UHE Sinop, 2010, p. 13).

Pesquisas que visam analisar a qualidade dos estudos de avaliação de impactos ambientais no Brasil (ALMEIDA; et.al, 2015; MONTAÑO; et.al, 2014), evidenciam a baixa qualidade destes estudos, em geral relacionada a falta de competência na sua coordenação e qualidade das análises técnicas. Situação similar é encontrada no EIA da UHE-Sinop, com graves falhas que comprometem diretamente a qualidade do estudo e sua capacidade de ser instrumentos para a gestão estratégica dos riscos associados. Não obstante isso, A UHE-Sinop é uma das seis hidrelétricas que estão em fase de construção no Rio Teles Pires, servindo de referência para as demais UHEs nesta bacia, motivo pelo qual se pressupõe que as falhas identificadas quanto a 
gestão dos riscos associados também estejam presentes nos EIA/RIMAs das outras 5 UHEs, construindo um cenário preocupante.

\subsection{PARECER DA SEMA E LICENCIAMENTO DA UHE-SINOP}

Em 10 de maio de 2012, a Secretaria de Especial do Meio Ambiente SEMA, órgão competente para análise EIA/RIMAs e concessão de Licença Prévia, emitiu parecer técnico referente aos Relatório apresentado pelo empreendimento UHESinop. O parecer reapresenta parte do RIMA da UHE-Sinop, indica a ausência de estudos sobre a flora e de alternativas socioeconômicas à pescadores e assentados, emitindo parecer favorável, condicionando a concessão da Licença Prévia ao cumprimento dessas exigências. Contudo, o parecer não faz qualquer referência a ausência de plano de gestão de riscos, principalmente os associados ao rompimento de barragem, com as respectivas medidas mitigadoras e de comunicação e participação social.

O EIA/RIMA tem, dentre suas finalidades, o de demonstrar a viabilidade ambiental do empreendimento e sua necessidade, frente à outras alternativas disponíveis, as quais também deveriam ter sido apresentadas no estudo e não o foram. Desta feita, um Estudo de Impacto Ambiental que não considera os riscos e os danos potenciais associados ao empreendimento, dentre outras falhas apontadas e não observadas pelo órgão fiscalizador, não é um instrumento capaz de embasar a decisão sobre a viabilidade ambiental, violando diretamente os princípios da prevenção e da precaução, informadores do Direito Ambiental.

\section{CONCLUSÕES}

O estudo permite concluir que é ainda recente a regulamentação de barragens no Brasil e que as exigências de segurança não vêm sendo atendidas. No estado de Mato Grosso, verifica-se a insuficiência de recursos materiais e humanos para a efetiva fiscalização e monitoramento da implementação dos Planos de Barragem, impactando na efetiva gestão dos riscos provenientes destes empreendimentos.

Os Estudos de Impacto Ambiental não vêm cumprindo sua finalidade, avaliando o potencial dos empreendimentos para causar impacto ambiental significativo e propondo medidas de mitigação e monitoramento, tendo em vista a efetivação da legislação ambiental e seus princípios. São produzidos estudos de baixa qualidade, que não deixam claras as metodologias empregadas, não apresentam alternativas ao R. Fac. Dir. UFG, v. 42, n. 3, p.202-224, set./dez. 2018 
Regulamentação de barragens em projetos para geração de energia elétrica e a gestão de risco

empreendimento para uma análise clara de sua necessidade e viabilidade frente aos impactos negativos do empreendimento.

Não obstante isso, os órgãos fiscalizadores, quando da análise do Estudo de Impacto Ambiental, não vêm considerando todos os elementos necessários, conforme previsão legal, para a liberação das licenças prévias, inferindo-se a ausência de conhecimento técnico como um dos elementos que contribuem para esta realidade. Diante desta conjuntura, vislumbra-se que os episódios de desastres no país, ligados ao rompimento de barragens, não refletiram como preocupação governamental, diante da ausência da estruturação dos órgãos responsáveis pela fiscalização destes empreendimentos, bem como na criação de legislação específica nos estados em relação à segurança de barragens e os riscos associados.

Ainda, em que pese a baixa qualidade do EIA/RIMA e o equivocado parecer técnico da SEMA e, considerando que a UHE-Sinop se encontra em fase de construção, vislumbra-se a necessidade de estudos relativos aos riscos associados, subsidiando a criação de uma plano de gestão dos riscos, minimizando as possibilidades de ocorrência de desastres no futuro, bem como garantindo, no caso de sua ocorrência, um plano de emergência eficaz.

\section{REFERÊNCIAS}

ANEEL. BIG. Banco de Informações de Geração, jan. 2018. Disponível em http://www2.aneel.gov.br/aplicacoes/capacidadebrasil/capacidadebrasil.cfm. Acesso em 05 de janeiro de 2018.

ALMEIDA, A.N. et al. Quality determinants of Environmental Impact Report. Revista Eletrônica em Gestão, Educação e Tecnologia Ambiental Santa Maria, v. 19, n. 2, mai-ago. p. 442-450, 2015.

ANA. (Agência Nacional de Águas). Relatório de Segurança de Barragens. Brasília, 2016. http://www.arquivos.ana.gov.br/segurança/RelatórioSegurancaBarragens_2015.pdf. Acesso em 10 de dezembro de 2017.

$$
\text { Brasília, }
$$

Disponível em:

http://www.arquivos.ana.gov.br/segurança/RelatórioSegurancaBarragens_2016.pdf. Acesso em 10 de fevereiro de 2018.

ARAGÃO, A. Desenvolvimento sustentável em tempo de crise e em maré de simplificação. Fundamento e limites da proibição de retrocesso ambiental. Estudos de 
Homenagem ao Prof. Doutor Gomes Canotilho. Coimbra: Coimbra Editora, p. 1-33, 2012.

Princípio da precaução: manual de instruções. Revista do Centro de Estudos de Direito do Ordenamento, do Urbanismo e do Ambiente. Coimbra: Faculdade de Direito de Coimbra, p. 9-57, 2008.

BERMANN, C. Impasses e controvérsias da hidroeletricidade. Estudos Avançados, v. 21, n. 59, p. 139-153, 2007.

BRASIL, Lei $n^{0}$ 6.938, 31 de agosto de 1981. Dispõe sobre a Política Nacional do Meio Ambiente, seus fins e mecanismos de formulação e aplicação, e dá outras providências.

Decreto $n^{\mathbf{0}}$ 88.351/83, 1 de junho de 1983. Regulamenta a Lei $\mathrm{n}^{\circ} 6.938$, de 31 de agosto de 1981, e a Lei $\mathrm{n}^{\circ}$ 6.902, de 27 de abril de 1981, que dispõem, respectivamente, sobre a Política Nacional do Meio Ambiente e sobre a criação de Estações Ecológicas e Áreas de Proteção Ambiental, e dá outras providências.

Lei n.9.433, de 8 de janeiro de 1997. Dispõe sobre a Política Nacional de Recursos Hídricos.

Lei n. ${ }^{\circ}$ 12.334, de 20 de setembro de 2010. Estabelece a Política Nacional de Segurança de Barragens destinadas à acumulação de água para quaisquer usos, à disposição final ou temporária de rejeitos e à acumulação de resíduos industriais, cria o Sistema Nacional de Informações sobre Segurança de Barragens e altera a redação do art. 35 da Lei ${ }^{\circ} 9.433$, de 8 de janeiro de 1997 , e do art. $4^{\circ}$ da Lei ${ }^{\circ} 9.984$, de 17 de julho de 2000 .

Resolução 143/2012, 10 de julho de 2012. Estabelece critério gerais de classificação de barragens por categoria de risco, dano potencial associado e pelo seu volume, em atendimento ao art. $7^{\circ}$, da Lei $\mathrm{n}^{\circ} 12.334$, de 20 de setembro de 2010.

Ministério da Integração Nacional. A Segurança de Barragens e a Gestão de Recursos Hídricos no Brasil / [Organizador, Rogério de Abreu Menescal]. Brasília: Proágua, 2005.

BECK, U. Sociedade de risco: rumo a uma outra modernidade. Trad. Sebastião Nascimento. 2 ed. São Paulo: Editora34, 2011.

COROMINAS J, et al. Glossary of Terms on Landslide Hazard and Risk. G. Lollino et al. (eds.), Engineering Geology for Society and Territory - Volume 2, p. 1775-1780, 2015.

EIRD, Estratégia Internacional para a Redução de Desastres. Marco de Ação de Hyogo 2005-2015: aumento da resiliência das nações e das comunidades frente aos desastres. Brasília: EIRD; Nações Unidas, 2007. Disponível em: <www.integracao.gov.br/cidadesresilientes/pdf/mah_ptb_brochura .pdf >. Acesso em 10 novembro de 2017 
Regulamentação de barragens em projetos para geração de energia elétrica e a gestão de risco

ENAP. Uma base para o desenvolvimento de estratégias de aprendizagem para a gestão de riscos no serviço público / Stephen Hill, Geoff Dinsdale; traduzido por Luís Marcos B. L. de Vasconcelos. Brasília: ENAP, 2003.

EPE. Plano Nacional De Energia - PNE 2030. Disponível em http://antigo.epe.gov.br//Estudos/Paginas/Plano\%20Nacional\%20de\%20Energia\%20\% E2\%80\%93\%20PNE/Estudos_12.aspx. Acesso em 05 de janeiro de 2018.

Informe de Planejamento da Expansão da Transmissão. Disponível em: http://www.epe.gov.br/sites-pt/publicacoes-dadosabertos/publicacoes/PublicacoesArquivos/publicacao271/Informe\%20Programa\%C3\%A7\%C3\%A3o\%20Estudos\%202018-final.pdf. Acesso em 05 de janeiro de 2018.

IBGE. Instituto Brasileiro de Geografia e Estatística. Disponível em: <http://www.ibge.gov.br> Acesso em: 8 de novembro de 2017.

MARSHALL, J. Tailings dams failures in Brazil and Canada: an assessment of corporate behavior. Caderno Eletrônico de Ciências Sociais, Vitória, v. 5, n. 1, pp. 2746, 2017.

MONTAÑO, M. et. al. Quality review of environmental impact statements applied to small hydropower plants. HOLOS Environment, v.14, n.1, 2014.

PINHO, P.; MAIA, R.; MONTERROSO, A. The quality of Portuguese Environmental Impact Studies: the case of small hydropower projects. Environmental Impact Assessment Review, Nem York, v. 27, p. 189-205, 2007.

SÁNCHEZ, L. E. Avaliação de impacto ambiental: conceitos e métodos. Editora Oficina de textos. 2006.

SAMPAIO, J. A. L. As deficiências do plano de ação emergencial das barragens no Brasil. Revista Brasileira de Direito, 12(2):, jul.-dez. p. 7-17, 2016.

TREASURY BOARD SECRETARIAT (TBS). Integrated risk management framework, 2001.

VEIGA, et. al. Diagnóstico das vazões do Rio Teles Pires. XX Simpósio Brasileiro de Recursos Hídricos. ABRH. Bento Gonçalves, Rio Grande do Sul. 2013. 
Artigo recebido em 30 de março de 2018 e aceito em 31 de dezembro de 2018

${ }^{1} \mathrm{O}$ rompimento da barragem sob responsabilidade da empresa mineradora Samarco em 2015, no município de Mariana, estado de Minas Gerais, Brasil, provocou a liberação de 62 milhões de $\mathrm{m}^{3}$ de rejeitos, formando uma onda de lama de aproximadamente 10 metros de altura, causando a destruição do Rio Doce, em cuja bacia viviam mais de 3,2 milhões de pessoas. A onda de lama, percorreu mais de $600 \mathrm{~km}$, inviabilizou o modo de vida de povos indígenas, atravessou os estados de Minas Gerais e Espírito Santo e atingiu o Oceano Atlântico, causando, assim, danos materiais elevados, perdas de vidas e degradação ambiental incalculável (Marshall: 2017).

${ }^{2}$ Disponível em: http://sinopenergia.com.br/show.aspx?idMateria=BTXuRdinzEpWiI5XbJspA. Acesso em 28 de fevereiro de 2018. 